\title{
A Mathematical Optimization Approach to Supply Chain Disruptions Management Considering Disruptions to Suppliers and Distribution Centers
}

\author{
Syed Mithun Ali \\ Department of Architecture, Civil Engineering and Industrial Management Engineering, Nagoya Institute \\ of Technology, Japan \\ E-mail:syed.mithun@gmail.com (Corresponding Author) \\ Koichi Nakade \\ Department of Architecture, Civil Engineering and Industrial Management Engineering, Nagoya Institute \\ of Technology, Japan \\ E-mail:nakade@nitech.ac.jp
}

\begin{abstract}
We develop an analytical framework of a multiproduct supply chain system composed of multiple suppliers, multiple distribution centers and multiple customers considering disruptions risk. Unlike traditional single sourcing strategy which is mostly discussed in supply chain literature, we apply multi-sourcing strategy in both procurement and distribution of commodities. The model thus developed determines the location of distribution centers from a set of potential location, shipment decisions from multiple suppliers to multiple distribution centers and shipment decisions from multiple distribution centers to multiple customers. Moreover, the model evaluates potential amount of products shortages in the event of disruptions. In our work, we consider disruptions at candidate locations for distribution centers and to the suppliers. The analytical framework is formulated as a mixed integer programming (MIP) model which minimizes the sum of investment cost, the transportation cost and the expected shortage cost. We consider several numerical instances to examine the benefit and practicability of the proposed model. Finally, we compare the results of the risk concern optimization framework to the basic optimization framework. From the results, it is expected that risk concern model would outperform the basic model in the case of disruptions.
\end{abstract}

Keywords: distribution centers disruptions, multi-echelon supply chain, supply chain disruptions, supply disruptions.

\section{INTRODUCTION}

In recent times, supply chain disruptions have gained increased attention from researchers and practitioners in the competitive business domains. Any events or collection of events that prevent a supply chain network from its regular operations might be defined as disruptions. Whatever might be the nature and magnitude of a disruption, it produces undesirable effects. For example, it might stop shop floors/distribution centers/warehouses from their day to day operations. In addition, it might stop flow of goods from one point to another in a network. Moreover, the on-hand raw material or finished products might be damaged due to disruptions. Therefore, disruptions hamper the entire plan of an organization thereby causing financial and reputational losses (Paul et al., 2014). Furthermore, it is advocated that designing a proper supply chain network is extremely important in order to facilitate overall business operations of an organization successfully (Chatzipanagioti at al., 2011). However, a well-designed supply chain might not perform up to its standard because of the presence of uncertainty (Wang \& Abareshi, 2014) and risks in the chain. Supply chain risks appear in a diversified nature on the different parts of a chain. Of all the various types of risks discussed in supply chain literature (Chopra \& Sodhi, 2004; Heckmann et al., 2015; Ma et al., 2010; Tang, 2006; Vilko \& Ritala, 2014), supply chain disruption risk is one of them. The interesting concept of disruptions management is firstly articulated by Clausen et al. (2001). They successfully apply the idea to airlines industry to resolve airline flight and crew scheduling problems. Next, the concept of disruption management appears for a wider range of applications such as production planning (Yang et al., 2005), machine scheduling (Qi et al., 2006), project scheduling (Zhu et al., 2005) and supply chain management (Qi et al., 2004).

Of recent, the widely accepted philosophy of lean inventory management makes the supply chain network of an enterprise sensitive and vulnerable to disruptions (GarciaHerrerros et al., 2013). Hendricks and Singhal (2005) report that supply chain disruptions has long term negative impacts on the supply chain financial performance. Further, a recent report by World Economic Forum shows that supply chain disruptions cut the share price of impacted companies by $7 \%$ on average (Bhatia et al., 2013). A very well-known example that highlights supply chain disruptions and effective response strategy is the case of Nokia-Ericsson in 2000. The Philip's microchips plant was shut down due to a fire accident. It caused Ericsson loss for about $\$ 400$ million, while Nokia managed to source from alternative suppliers thus minimized the disruption effect (Latour, 2001). In the last decade, the word experiences a series of natural disasters. The disasters 
show an escalating effect on the deterioration of the global supply chain performance. In 2013, 330 natural disasters were reported with huge economic impact (Guha-sapir et al., 2013). Actually, some high profile disasters that disrupt supply chain globally and force decision makers to think about supply chain disruptions are Hurricane Katrina and Rita in 2005, Indian Ocean earthquake and tsunami 2004, Japan earthquake and tsunami 2011, terrorist attacks 9/11 (Ali \& Nakade, 2014).

There are some studies that recognize the effect and importance of considering disruptions in supply chain (Chopra \& Sodhi, 2004; Craighead et al., 2007; Kim et al., 2015; Rice Jr \& Caniato, 2003). They emphasize on risk handling strategies into the supply chain design. Despite the fact that managing supply chain disruptions are increasingly important in managing business resilience and continuity (Falasca, Zobel \& Cook, 2008), little academic literature addresses the issues vibrantly thus far. In recent years, some authors suggest dual and/or multiple sourcing as one of the effective strategies to cope with supply chain disruptions risk (Ali \& Nakade, 2014; Kelle \& Miller, 2001; Parlar \& Perry, 1996; Tomlin, 2006; Xia \& Matsukawa, 2014; Xiaoqiang \& Huijiang, 2009; Yu et al., 2009). Right after the Japan disasters in 2011, the drive towards multiple sourcing from traditional single sourcing strategy has been started in practice to the decision makers in the area of supply chain operations. Though multiple sourcing strategies offer higher reliability in the supply chain of an enterprise, it adds more cost (Moritz \& Pibernik, 2008). Traditional supply chain design problems deal with the issues of facility location problems (FLP) (Melo et al., 2009; Raftani-amiri et al., 2010; Shariff et al., 2010). The theory of the location of industries is proposed by Weber and Friedrich (1929). Since then, facility location problems (FLP) get enormous attention to the researchers as shown from the review articles (Meixell \& Gargeya, 2005; Owen \& Daskin, 1998; Shen, 2007) and some of the recent works on FLP (Bieniek, 2015; Dantrakul et al., 2014; Ho, 2015). In traditional supply chain design, it is assumed that the facilities will always remain in operation to provide service to customers. However, disruptions to the entities of a supply chain system are very common and almost inevitable in a complex and interdependent networks (Ali \& Nakade, 2014; Hishamuddin et al., 2014; Schmitt \& Singh, 2012). Despite the ever increasing importance of emphasizing disruptions in decision making of an organization, studies on facility location problems considering disruptions risks are few in supply chain literature.

Some authors investigate and link facility disruptions in the facility location problems in recent times. Azad et al. (2013) study the design problem of a reliable stochastic supply chain network. They consider random disruptions in the location of DCs and the transportation modes. They mitigate the effect of disruption through transporting goods from non-disrupted DCs to disrupted DCs. Baghalian et al. (2013) develop a mathematical formulation for a multiproduct multi-echelon supply chain considering disruptions in manufacturers, distribution centers and their connecting links. Cui et al. (2010) formulate a mixed integer programming model and a continuum approximation model to study the reliable uncapacitated fixed-charge location problem (UFLP). They minimize the initial setup cost and the expected transportation cost in normal and failure scenarios. Snyder \& Daskin (2005) formulate a reliability models based on the P- median problem (PMP) and the uncapacitated fixed-charge location problem (UFLP). They minimize operating cost while taking into consideration the expected transportation cost after failure of facilities. They apply Lagrangian relaxation algorithm to solve the model. Atoei et al. (2013) offer a supply chain network design model considering disruptions risk in both distribution centers and suppliers. Their model determines optimal location of distribution centers, assignment of customers and suppliers to nondisrupted DCs and transporting goods from non-disrupted DCs to disrupted DCs in the event of disruptions. Further, they model reliability of DCs in the work. In addition, Jabbarzadeh et al. (2012) design a supply chain network and formulate a nonlinear mixed integer programming model to incorporate facility disruptions. Their model determines facility location decisions, customer allocation decisions and cycle order quantities at facilities. They follow single sourcing strategy in their framework. Ghomi-Avili et al. (2013) study facility failures and breakdown thus linking facility location with the disruptions risk of a supply chain that procures and distributes a single product. They classify the distribution centers as reliable and unreliable categories. In their work, the unreliable distribution centers are subject to failures. They solve the mathematical model using CPLEX and simulated annealing algorithm. Li et al. (2013) study the design of a reliable facility location problem considering heterogeneous facility failure probabilities. They formulate two nonlinear models: a reliable P-median problem (RPMP) and a reliable uncapacitated fixed-charge location problem (RUFL). They solve the models using Lagrangian relaxation (LR) approach and a myopic policy approach. They apply one layer supply backup in the models.

In view of the perspectives of risk concern supply chain architecture, this paper addresses the design of a multi-product multi-echelon supply chain consisting of multiple suppliers, multiple distribution centers and multiple customers while focusing on disruptions risk. In most of the supply chain literature discussed above, single sourcing strategy with disruptions to suppliers or distribution centers is adopted. In this work, we follow multi-sourcing strategy in both procurement and distribution decisions. Hence, our work provides a multi-multi allocation (MMA) model in practice.

Moreover, we consider disruptions to suppliers and distribution centers. The goal of our work is to build a risk concern supply chain optimization framework considering disruptions risk in a multi-echelon supply chain environment. The problem determines location of distribution centers and establishing a procurement and distribution strategy while taking into consideration the potential disruptions at DC locations and to the suppliers. The cost considered here is the sum of investment cost, the sum of transportation cost in procurement and distribution and the expected shortage cost while the system undergoes disruptions.

For better understanding of the optimization framework, a definition of the different terms used in this paper is given below:

Disruptions: Any form of events/irregularities that hamper normal operation of a supply chain system. These events might include machine shutdown/machine breakdown, labor 
strike, natural disasters, and accidents in production, storage or transportation facilities etc.

Scenarios: While disruptions happen in any supply chain system, it negatively affects the system. The system therefore cannot respond as in the case of normal operating conditions. We say that when disruptions take place at the production facilities and storage/delivery facilities, those can't supply the regular amount to their downstream side. To capture this effect, we consider several scenarios. Under a disrupted condition, each scenario expresses the percentage of normal supply amount in the system.

Shortage cost: In our system, the distribution centers receive goods from the suppliers. Then the products undergo some operations like labelling and packaging and then those are carried to the customers (retailers). Due to disruptions to the suppliers or at the distribution centers, the distribution centers can't meet the demand of the customers. We model this as a shortage penalty cost for unsatisfied demand. It is noted that this might be a lost sales cost or the cost of purchasing the products from a local supplier. The concept of keeping a backup supplier is found in the work of Ali \& Nakade (2014).

The rest of the paper is organized as follows. Section 2 describes the problem statement. Section 3 states the mathematical formulation. Section 4 illustrates the related computational experiment. Finally, Section 5 draws conclusion of the paper.

\section{PROBLEM STATEMENT}

This paper involves formulation of an optimization framework of a multi-product, multi-echelon supply chain subject to supply and storage facility disruptions. The supply chain consists of multiple suppliers, one or more distribution centers (DCs), and multiple customers as shown in Figure 1. A family of products $(l \in L)$ is outsourced from multiple suppliers $(i \in I)$ and then shipped to the distribution centers $(j \in J)$. Afterwards, the received products are shipped from the distribution centers to the customers $(k \in K)$. Our problems involve selecting DCs among a set of candidate locations, the number of DCs to be selected and establishing distribution strategy while considering disruptions at the location of distribution centers (DCs) and to the suppliers. For the sake of simplicity of analysis, two assumptions are made herein. First, it is assumed that each and every distribution centers can receive products from each of the suppliers. Second, each customer receives products from each of the distribution centers. Therefore, our strategy is a multi-multi allocation (MMA) strategy in both procurement and distribution of the products. The objective of our work is to minimize the sum of investment cost, the transportation cost and the expected shortage cost in the event of disruptions. We further assume that the supplies from the suppliers and from the DCs are partially disrupted while disruptions happen. In addition, it is pointed out that while disruptions happen to the suppliers, the products received to the distribution centers in the subsequent time periods would be lower than the regular flow amount. In the time period when the system is recovered from disruptions, the suppliers start to supply regular flow amount. Further, while suppliers and DCs are disrupted, the system cannot meet all the demand of

the customers. In this case, the system might incur shortage cost for unsatisfied demand. This cost might be a lost sales cost or the cost of purchasing the products from a local supplier during disruptions. It is noted here that we are not interested to explore the cases of complete failure of suppliers and/or facilities that might turn out a supply chain to be out of service partially or totally thus imposing a threat on organizational existence.

In our work, a scenario-based approach is followed to track the reduction in supplies of the suppliers and the location of distribution centers (DCs). The values of reduction in supplies are generated from normal distribution. Each scenario specifies the percentage of supply that is supplied from the suppliers and from the distribution centers when the system suffers disruptions. Based on these observations, the amount of unsatisfied demand and the associated shortage cost are determined. The scenario probability is generated as a uniformly distributed random parameter. The expected shortage cost is evaluated by multiplying the scenario probability to the associated shortage cost summed over all the scenarios.

In the next section, we describe the mathematical formulation of our work.

Suppliers

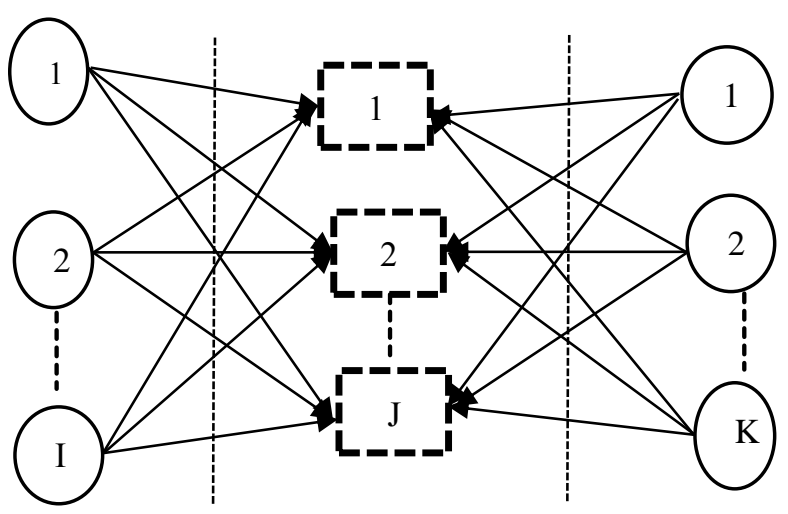

Figure 1. Schematic diagram of a multiproduct multiechelon supply chain

\section{FORMULATION}

The following nomenclature is used in this paper: Sets

I index set of suppliers $i$

$J \quad$ index set of candidate locations for $j \mathrm{DCs}$

$K \quad$ index set of customers $k$

$L \quad$ index set of commodities $l$

$S \quad$ index set of scenarios $S$

\section{Variables}

$X_{j} \quad$ Binary variable deciding whether DC at candidate location $j$ is selected

$Z_{i j l} \quad$ Amount of commodity $l$ shipped from supplier $i$ to $\mathrm{DC} j$

$y_{j k l} \quad$ Amount of commodity $l$ shipped from $\mathrm{DC} j$ to customer $k$ 
$Q_{j k l s}^{1} \quad$ Amount of shortage of commodity $l$ for customer $k$ at DC $j$ at first time period in scenario $s$

$Q_{j k l s}^{2} \quad$ Amount of shortage of commodity $l$ for customer $k$ at DC $j$ at second time period in scenario $s$

$y_{j k l s}^{2} \quad$ Amount of commodity $l$ for customer $k$ that is supplied from DC $j$ at second time period in scenario $s$

\section{Parameters}

$D_{k l} \quad$ Demand of customer $k$ for commodity $l$ per time period

$F_{j} \quad$ Fixed investment cost of DC $j$ per time period

$A_{i j l} \quad$ Transportation cost per unit of commodity $l$ from supplier $i$ to $\mathrm{DC} j$

$B_{j k l} \quad$ Transportation cost per unit of commodity $l$ from DC $j$ to customer $k$

$\mathrm{Cap}_{j} \quad$ Storage capacity of DC $j$

$P_{i} \quad$ Production capacity of supplier $i$

$\pi_{s} \quad$ Probability of scenario $s$

$\alpha_{i s l} \quad$ A fraction of supply from supplier $i$ of product $l$ in scenario $s . \forall i \in I, l \in L, s \in S$

$\beta_{j s l} \quad$ A fraction of supply from DC $j$ of product $l$ in scenario $s . \forall i \in I, l \in L, s \in S$

$n_{l} \quad$ Space requirement rate of product $l$

$m_{l} \quad$ Capacity utilization rate of product $l$

$\gamma_{l k} \quad$ Penalty cost per unit of unsatisfied demand of product $l$ for customer $k$ (It may be a lost sales cost or the cost of purchasing the product from local market during disruptions)

$R$ The number of distribution centers required to be located

\section{Model assumptions}

The assumptions associated with the model are listed below:

(a) Suppliers are not reliable and their production capacities are limited.

(b) Distribution centers storage capacities are limited.

(c) Suppliers and customers' locations are fixed. The distribution centers are required to be located.

(d) Demand is stochastic and uniformly distributed.

(e) The magnitude of disruptions is such that suppliers and distribution centers can't supply the regular flow amount in the event of disruptions. The percentage of supply from the suppliers and the distribution centers subject to disruptions is stochastic and follows a random normal distribution.

\section{Mathematical model:}

The minimization of the total cost comprises of the following parts of the objective functions:

1. The total fixed cost for locating/renting distribution centers, given by the term:

$\sum_{j \in J} F_{j} X_{j}$

This fixed cost is assumed as the cost incurred per unit time period. For example, cost of renting a facility for a day/a week/a month etc.

2. The cost of shipping goods from multiple suppliers to multiple distribution centers (DCs) and the cost of shipping goods from multiple distribution centers (DCs) to multiple customers. Every supplier can ship goods to each of the distribution centers. And every distribution centers can ship goods to each of the considered customers. Transportation cost is calculated by multiplying unit transportation cost to the amount of products shipped. The cost thus becomes

$$
\sum_{i \in I} \sum_{j \in J} \sum_{l \in L} Z_{i j l} A_{i j l}+\sum_{j \in J} \sum_{k \in K} \sum_{l \in L} y_{j k l} B_{j k l}
$$

3. The expected shortage cost in the event of disruptions is given by the following two terms. The first term represents the expected shortage cost in the first time period due to disruptions at the distribution centers. On the other hand, the second term represents the expected shortage cost in the second time period. Due to disruptions to the suppliers in the first time period, the amount of products received at the distribution centers in the second time period would be lower than the regular amount. The shortage cost is calculated by multiplying unit shortage cost to the shortage amount in the first and second period. The expected shortage cost equals the product of the scenario probability and the associated shortage cost summed over all the scenarios considered.

$$
\sum_{s \in S} \pi_{s}\left\{\begin{array}{c}
\sum_{j \in J} \sum_{k \in K} \sum_{l \in L} \gamma_{l k} Q_{j k l s}^{1} \\
+\sum_{j \in J} \sum_{k \in K} \sum_{l \in L} \gamma_{l k} Q_{j k l s}^{2}
\end{array}\right\}
$$

Thus, the optimization problem is formulated as follows:

$$
\begin{gathered}
\text { Minimize } u= \\
\sum_{j \in J} F_{j} X_{j}+\sum_{i \in I} \sum_{j \in J} \sum_{l \in L} Z_{i j l} A_{i j l}+ \\
\sum_{j \in J} \sum_{k \in K} \sum_{l \in L} y_{j k l} B_{j k l}+ \\
\sum_{s \in S} \pi_{s}\left\{\begin{array}{c}
\sum_{j \in J} \sum_{k \in K} \sum_{l \in L} \gamma_{l k} Q_{j k l s}^{1} \\
+\sum_{j \in J} \sum_{k \in K} \sum_{l \in L} \gamma_{l k} Q_{j k l s}^{2}
\end{array}\right\}
\end{gathered}
$$

Subject to,

$\sum_{j \in J} X_{j}=R$

$\sum_{i \in I} Z_{i j l}=\sum_{k \in K} y_{j k l} \quad \forall j \in J, l \in L$

$\sum_{i \in I} \sum_{l \in L} Z_{i j l} \leq M X_{j}$

$\forall j \in J$

$\sum_{k \in K} \sum_{l \in L} y_{j k l} \leq M X_{j} \quad \forall j \in J$

$\sum_{j \in J} y_{j k l}=D_{k l} \quad \forall l \in L, k \in K$

$\sum_{l \in L} m_{l} \sum_{j \in J} Z_{i j l} \leq P_{i} \quad \forall i \in I$

$\sum_{l \in L} n_{l} \sum_{k \in K} y_{j k l} \leq \operatorname{Cap}_{j} X_{j} \quad \forall j \in J$

$\sum_{j \in J} Q_{j k l s}^{1} \geq D_{k l}-\sum_{j \in J}\left(\beta_{j s l} * y_{j k l}\right)$

$\forall l \in L, k \in K, s \in S$

$\sum_{j \in J} Q_{j k l s}^{2} \geq D_{k l}-\sum_{j \in J} y_{j k l s}^{2}$

$\forall l \in L, k \in K, s \in S$

$\sum_{k \in K} y_{j k l s}^{2}=\sum_{i \in I} \alpha_{i s l} * Z_{i j l} \quad \forall l \in L, k \in K, s \in$

$S$

$X_{j} \in\{0,1\} \quad \forall j \in J$

$y_{j k l}, Z_{i j l}, Q_{j k l s}^{1}, y_{j k l s}^{2} \geq 0 \quad \forall j \in J, l \in L, k \in$

$K, s \in S$

Equation (1) is the objective function. It minimizes the sum of investment cost at DCs, the sum of distribution cost from supplier to DCs and from DCs to customers, the sum of expected shortage cost. Equation (2) states that $\mathrm{R}$ numbers of distribution centers are to be located. Equation (3) is the mass balance constraint. Constraint (4) ensures restriction of flow of products from supplier $i$ to distribution center $j$ before establishment of distribution center $j$. Constraint (5) ensures that flow can't be initiated from distribution center $j$ to customer $k$ until we establish 
distribution center $j$. In equation (4) and (5), $\mathrm{M}$ is a sufficiently large positive number. Equation (6) implies demand satisfaction constraint. Constraint (7) is the capacity constraint of the supplier. Constraint (8) expresses capacity constraints of the distribution centers. Constraint (9) represents amount of shortage in the first time period. Constraint (10) indicates amount of shortage in the second time period. Constraint (11) decides the amount of product supplied to the distribution centers in the second time period due to disruptions of the suppliers in the first time period. As the suppliers suffer disruptions in the first time period, they can't supply the normal flow amount $\left(Z_{i j l}\right)$ in the second time period, rather some fraction of those amount are provided by those to the distribution centers. Constraint (12) imposes the integrality restrictions on binary variable. Finally, constraint (13) enforces the non-negativity restriction on the corresponding decision variables.

\section{COMPUTATIONAL EXPERIMENT}

Several sets of numerical examples are designed and implemented in order to demonstrate the applicability and usefulness of the proposed model. In order to highlight the significance of considering disruptions in supply chain planning and decision making, a comparison is made between the proposed model with an emphasis on disruption risk and the basic or baseline model. A basic or baseline model is the one which is designed and operated in a condition assuming that there would be no disruptions. Most of the traditional supply chains ignore disruptions arguing those as rare events. However, the effects of disruptions seem to have catastrophic consequences on organizational existence (Knemeyer et al., 2009). In this numerical investigation, we show the effect of disruptions in terms of monetary value.

Table 1 Range of Data of The Test Problems

\begin{tabular}{|l|l|}
\hline Parameters & Range of data \\
\hline $\begin{array}{l}\text { Investment cost for operating } \\
\text { DCs,(\$) }\end{array}$ & Uniform $[100,300]$ \\
\hline Product demand & Uniform[2000,3500] \\
\hline $\begin{array}{l}\text { Fraction of supply [Supplier to } \\
\text { DC] }\end{array}$ & Normal $[0.70,0.10]$ \\
\hline $\begin{array}{l}\text { Fraction of supply [DC to } \\
\text { Customer] }\end{array}$ & Normal $[0.80,0.10]$ \\
\hline $\begin{array}{l}\text { Transportation cost /supplier to } \\
\text { DC,(\$) }\end{array}$ & Uniform[0.015,0.25] \\
\hline $\begin{array}{l}\text { Transportation cost /DC to } \\
\text { customer, (\$) }\end{array}$ & Uniform[0.025,0.45] \\
\hline $\begin{array}{l}\text { Penalty cost per unit of } \\
\text { shortage cost (\$) }\end{array}$ & Uniform[0.55,1] \\
\hline Space utilization rate & Uniform $[2,5]$ \\
\hline Capacity utilization rate & Uniform $[2,5]$ \\
\hline DC storage capacity & Uniform [1200,1500] \\
\hline Supplier Production capacity & Uniform $[2000,4000]$ \\
\hline
\end{tabular}

We consider several sample examples having different dimensions in terms of number of distribution centers, number of customers to be served and number of products to be provided from the suppliers and from the distribution centers. Each of the suppliers and each of the distribution centers can serve every type of products. Table 1 shows the range of data of the test problems. We initiate our numerical experiment considering a small representative supply chain consisting of four potential DCs locations, three outside suppliers, three products and five customers located at different locations in a territory. We vary the number of potential sites for renting or establishing distribution centers, the number of customer to be served by the DC and the number of products to be provided in the system. We thus formulate 10 test problems (T1-T10) which are shown in Table 2. The number of distribution centers required for optimum solution is determined from the process of simulation. For every test instance, we have the input such as number of potential DCs, number of products, number of suppliers and number of products along with other parameters presented in Table 1. Under these settings, we start the experiment by putting the value of the number of DCs required to be located for optimum network configuration equals one. If the problems seem infeasible, then in the next trial we add another distribution center. In this way we find the number of distribution centers to be located for getting optimum solution. We consider 100 scenarios to test the model for each of the 10 test instances. The probability of scenario is generated from a uniformly distributed random variable defined in $U[0,1]$ and then normalized to ensure that the sum of all probabilities is equal to one. In each scenario, we have the percentage of regular supply that is flown to downstream supply chain echelon. The values of fraction of supply are generated from a normally distributed random variable. The fraction of supply from suppliers to distribution centers is treated as normally distributed with mean 0.70 and standard deviation 0.10 . The fraction of supply from distribution centers to customers is also considered as normally distributed with mean 0.80 and standard deviation 0.05 respectively. The capacity of distribution centers and suppliers are defined as uniformly distributed random variable in U[1200,1500] and U[2400,3000] respectively. The space and capacity utilization rate are also drawn as uniformly distributed random variable in U[2,5] as in the work of Sahraeian et al. (2010). The mathematical model presented in this paper is coded on GAMS 24.1.3 and run by CPLEX 12.5.1.0 solver on an Intel (R) Core (TM) i7-3770 Dual Processor with 24GB RAM and a $3.40 \mathrm{GHz}$ CPU. Table 3 illustrates a comparison of results between the risk-concern and the basic model in terms of the objective function value (OFV) and solution time. Moreover, some results related to the decision variables for both of the models are shown in Table 4. It is observed in Table $\mathbf{3}$ that the basic model converges quite faster than the risk concern model. In addition, in contrast to the risk concern model, the basic model demands significantly lower cost due to the absence of disruptions handling cost. In this stage, we find the solutions with satisfactory processing time for all of the sets of computational domain. 
Table 2. Sample Examples in Terms of Number of DCs /Customers/Products in Different Sizes

\begin{tabular}{|c|c|c|c|c|c|}
\hline $\begin{array}{c}\text { Test } \\
\text { instance }\end{array}$ & Suppliers & $\begin{array}{c}\text { Potential sites for } \\
\text { establishing DCs }\end{array}$ & $\begin{array}{c}\text { Number of DCs } \\
\text { required }\end{array}$ & $\begin{array}{c}\text { Number of } \\
\text { customers }\end{array}$ & $\begin{array}{c}\text { Number of } \\
\text { of products }\end{array}$ \\
\hline T-1 & 3 & 4 & 1 & 5 & 3 \\
\hline T-2 & 3 & 6 & 1 & 8 & 4 \\
\hline T-3 & 3 & 8 & 1 & 10 & 12 \\
\hline T-4 & 3 & 10 & 1 & 15 & 6 \\
\hline T-5 & 3 & 12 & 2 & 20 & 8 \\
\hline T-6 & 3 & 15 & 5 & 25 & 10 \\
\hline T-7 & 3 & 18 & 12 & 30 & 10 \\
\hline T-8 & 3 & 20 & 14 & 35 & 10 \\
\hline T-9 & 3 & 25 & 17 & 50 & 10 \\
\hline T-10 & 3 & 40 & 32 & \\
\hline
\end{tabular}

Table 3. Objective Function Values and CPU Time for The Risk Concern and Basic Model

\begin{tabular}{|c|c|c|c|c|c|}
\hline \multirow{2}{*}{$\begin{array}{c}\text { Test } \\
\text { instance }\end{array}$} & \multicolumn{2}{|c|}{ Objective function value (\$) } & \multirow{2}{*}{$\begin{array}{l}\text { Additional cost } \\
\text { due to disruptions (\$) }\end{array}$} & \multicolumn{2}{|c|}{ CPU time (Secs) } \\
\hline & Risk concern model & $\begin{array}{l}\text { Basic model ( no } \\
\text { disruptions) }\end{array}$ & & $\begin{array}{l}\text { Risk concern } \\
\text { model }\end{array}$ & $\begin{array}{l}\text { Basic } \\
\text { model }\end{array}$ \\
\hline $\mathrm{T}-1$ & $27,527.372$ & 7548.754 & $19,978.618$ & 0.34 & 0.03 \\
\hline $\mathrm{T}-2$ & $54,272.575$ & $22,705.126$ & $31,567.449$ & 12.01 & 0.05 \\
\hline T-3 & $81,696.390$ & $36,379.457$ & $45,316.933$ & 94.52 & 0.05 \\
\hline $\mathrm{T}-4$ & $107,693.332$ & $47,008.906$ & $60,684.426$ & 239.31 & 0.05 \\
\hline $\mathrm{T}-5$ & $176,443.580$ & $65,819.344$ & $110,624.236$ & 771.17 & 0.66 \\
\hline $\mathrm{T}-6$ & $214,998.248$ & $66,355.032$ & $148,643.216$ & 830.22 & 0.89 \\
\hline $\mathrm{T}-7$ & $319,819.098$ & $73,501.352$ & $246,317.746$ & 670.43 & 0.22 \\
\hline $\mathrm{T}-8$ & $379,534.944$ & $84,029.642$ & $295,505.302$ & 563.54 & 0.23 \\
\hline T-9 & $420,403.170$ & $94,385.226$ & $326,017.944$ & 438.25 & 0.55 \\
\hline $\mathrm{T}-10$ & $593,996.896$ & $111,716.436$ & $482,280.46$ & 631.91 & 0.47 \\
\hline
\end{tabular}

It is observed that the inclusion of disruption adds cost in the systems which are explicitly shown in Figure 2. This cost is modeled as penalty cost for shortages of products for disruptions. This penalty cost might be lost sales cost or the cost of purchasing the products from a competitor. Figure 2 reports significantly higher cost difference between risk concern and basic model in particular for serving higher number of customers. Roughly, the range of the objective function values for the risk concern model approximates two to five times higher cost than the basic model. It is pointed out that the high cost difference between risk concern and basic framework depends on the extent of per unit penalty cost. Management can fix per unit penalty cost based on experience and personal judgments and can formulate different strategies and action plans in the case of disruptions. The monetary comparisons between risk concern and basic model highlights the impacts and significance of considering disruptions on today's dynamic supply chains which are mostly vulnerable and fragile to man-made and natural disasters. It is believed that disruptions are low probability but high impact events. But, the aftermath effects of disruptions in terms of production, financial and reputational losses influence the decision makers of global supply chain to rethink and reengineer their business models considering disruptions risk. Consequently, the investigation upholds significant insights for the policy making of an enterprise that seeks to mitigate the catastrophic effects of supply chain disruptions. The analysis made in our works offers some benefits to supply chain decision making of an organization. On comparing disruptions cost/disruptions recovery cost with normal operating cost, management of an organization can decide on strategies to mitigate or cope with supply chain disruptions. They can adapt to supply chain disruptions by following strategies such as emergency sourcing from a supplier or offering back-ordered sales to customers. On the other hand, they can be mentally prepared to accept the effects of disruptions and experience lost sales thereby. Table 4 shows some comparisons of the decision variables for the basic model and the risk concern model.

Table 4. Some Results from the Test Instance T-1

\begin{tabular}{|l|l|l|l|}
\hline \multicolumn{2}{|l|}{ Basic model } & Risk concern model \\
\hline Decision variables & Solution & Decision variables & solution \\
\hline$X$ (location) & $J_{4}$ & $X$ (location) & $J_{3}$ \\
\hline $\begin{array}{l}Z_{\text {il }} \text { (Shipped amount } \\
\text { from suppliers) }\end{array}$ & $\begin{array}{l}\text { Zijl (Shipped amount } \\
\text { from suppliers) }\end{array}$ \\
\hline
\end{tabular}


Table 4 Some Results from the Test Instance T-1 (Con't)

\begin{tabular}{|l|l|l|l|}
\hline I1J4L3 & 14013.975 & I1J3L1 & 13169.348 \\
\hline I2J4L2 & 13578.566 & I2J3L2 & 12502.068 \\
\hline I3J4L1 & 11941.535 & I2J3L3 & 14077.643 \\
\hline \multicolumn{2}{|l|l|}{} & I3J3L1 & 982.236 \\
\hline Yjkl (Shipped amount from DCs) & 2375.121 & Y jk1 (Shipped amount from DCs) \\
\hline J4K1L1 & J3K1L1 & 3300.768 \\
\hline J4K1L2 & 3003.393 & J3K1L2 & 2342.572 \\
\hline J4K1L3 & 2653.035 & J3K1L3 & 3405.198 \\
\hline J4K2L1 & 2539.550 & J3K2L1 & 2963.597 \\
\hline J4K2L2 & 2527.162 & J3K2L2 & 2317.229 \\
\hline J4K2L3 & 2197.237 & J3K2L3 & 2043.519 \\
\hline J4K3L1 & 2225.153 & J3K3L1 & 2763.387 \\
\hline J4K3L2 & 2883.670 & J3K3L2 & 2698.522 \\
\hline J4K3L3 & 3264.339 & J3K3L3 & 2970.689 \\
\hline J4K4L1 & 2346.224 & J3K4L1 & 2532.766 \\
\hline J4K4L2 & 2998.602 & J3K4L2 & 2186.748 \\
\hline J4K4L3 & 3163.786 & J3K4L3 & 3192.872 \\
\hline J4K5L1 & 2455.488 & J3K5L1 & 2591.065 \\
\hline J4K5L2 & 2165.738 & J3K5L2 & 2956.996 \\
\hline J4K5L3 & 2753.577 & J3K5L3 & 2465.365 \\
\hline
\end{tabular}

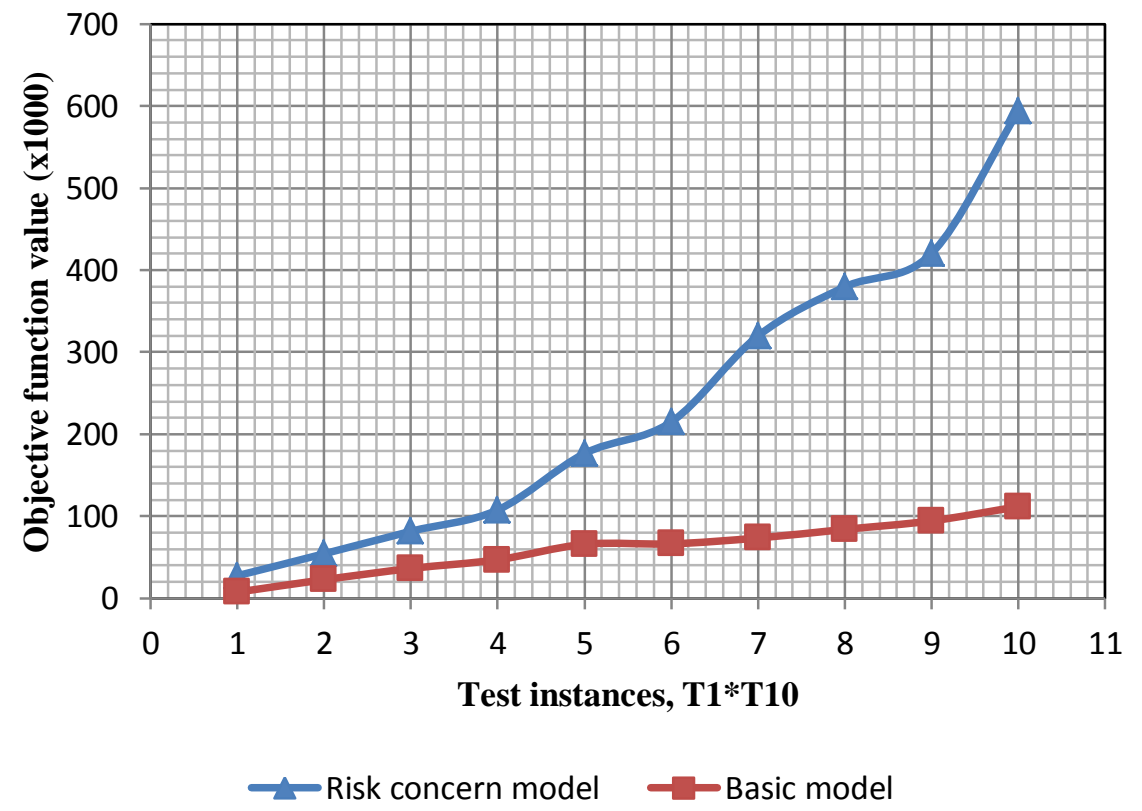

Figure 2. Comparison of Cost Between Risk Concern and Basic Model

Table 4 shows some interesting observations that are worth pointing out. We see that the solutions of the decision variables are changed when we include disruptions risks in the supply chain system we consider for our work. First we notice the selection of the distribution centers (DCs) location. It is identified that location $\mathrm{J} 4$ is selected in the case of basic model whereas $\mathrm{J} 3$ is selected while we consider disruptions risk in the model. Second, the variation of shipment decisions is also seen from Table 4. The reasons behind the observations might be explained from two aspects. Firstly, we consider several scenarios in order to capture the effect of disruptions for both the supply and distribution system. Secondly, we assign cost for the amount of products shortages due to disruptions. Therefore, to minimize the effects and the associated cost of disruptions and disruptions mitigation, an alternative solution seems to have in our analysis. Thus it is concluded that inclusions of disruptions risk trigger the strategic planning and decision making of a supply chain system to hedge against unexpected supply chain disruptions.

Some features of the optimization instances are shown in Table 5. It is seen that for larger problem size we have huge numbers of individual equations and individual variables. Table 5 also shows the number of binary variables used in the model. 
Table 5. Some Features of the Optimization Instances

\begin{tabular}{|c|c|c|c|}
\hline $\begin{array}{c}\text { Test } \\
\text { instance }\end{array}$ & $\begin{array}{c}\text { \#of single } \\
\text { equations }\end{array}$ & $\begin{array}{c}\text { \# of single } \\
\text { variables }\end{array}$ & $\begin{array}{c}\text { \# of discrete } \\
\text { variables }\end{array}$ \\
\hline T-1 & 4,244 & 18,101 & 4 \\
\hline T-2 & 8,879 & 57,871 & 6 \\
\hline T-3 & 14,119 & 120,529 & 8 \\
\hline T-4 & 20,567 & 216,911 & 10 \\
\hline T-5 & 33,857 & 433,741 & 12 \\
\hline T-6 & 44,330 & 722,776 & 15 \\
\hline T-7 & 68,489 & $1,355,059$ & 18 \\
\hline T-8 & 80,565 & $1,806,621$ & 20 \\
\hline T-9 & 95,680 & $2,634,526$ & 25 \\
\hline T-10 & 141,025 & $6,021,241$ & 40 \\
\hline
\end{tabular}

In this stage, we consider a separate set of experiment with a view to exploring the behavior of the model under several numbers of scenarios. Thus for conducting the simulation experiments, we consider the test instance T-5 and examine the effects of different number of scenarios on the objective function values (OFV). We begin the experiment considering ten scenarios and terminate the simulation when it reached one hundred scenarios. The results obtained from the investigation are presented in Table 6. It is evident from Table 6 that for higher number of scenarios the CPU time increases. The reasons behind this phenomenon are that when numbers of scenarios are large, we have more decision variables and more constraints. So, it takes more time to find the optimal solution. The values of objective function over all the scenarios are presented in Figure 3. For smaller number of scenarios, the values of objective functions are a bit higher than higher number of scenarios. As the sum of all scenario probabilities is one, for higher number of scenarios the expected costs tend to become lower. Therefore, values of objective function are lower for a larger number of scenarios. Thus, the model shows satisfactory performance up to this domain of experimental investigations.

Table 6. Objective Function Values (OFB) and CPU Time for Different Number of Scenarios for Test Instance T-5

\begin{tabular}{|c|c|c|c|}
\hline No. & \#of Scenarios & $\begin{array}{c}\text { Objective Function } \\
\text { values (OFB), } \$\end{array}$ & $\begin{array}{c}\text { Solution } \\
\text { time } \\
(\text { Secs })\end{array}$ \\
\hline 1 & 10 & $185,092.623$ & 27.04 \\
\hline 2 & 20 & $193,043.674$ & 90.22 \\
\hline 3 & 30 & $188,009.427$ & 154.47 \\
\hline 4 & 40 & $182,936.271$ & 247.22 \\
\hline 5 & 50 & $177,050.374$ & 285.56 \\
\hline 6 & 60 & $181,019.883$ & 359.04 \\
\hline 7 & 70 & $178,102.231$ & 495.66 \\
\hline 8 & 80 & $180,918.821$ & 643.21 \\
\hline 9 & 90 & $179,763.746$ & 665.72 \\
\hline 10 & 100 & $176,443.580$ & 771.17 \\
\hline
\end{tabular}

\section{CONCLUSION}

In the $21^{\text {st }}$ century, the key to business success and business continuity would rely on effective response and recovery from supply chain disruptions. Increasingly, considering and managing disruptions risk has become one of the important concerns in modern business paradigm over traditional philosophies. This paper addresses the issues of formulating an analytical framework of a multi-commodity multi-stage supply chain considering disruptions risk at the location of distribution centers (DCs) and suppliers. We formulate a mixed integer programming (MIP) model and solve by GAMS/CPLEX software. Decisions such as number and location of distribution centers, distribution strategies from suppliers to distribution centers (DCs) and from distribution centers (DCs) to customers and amount of shortages due to potential disruptions are considered. Unlike traditional supply chain literatures, we allow multiple sourcing strategy in both procurement and distribution decisions. This philosophy adds flexibility to deal with disruptions in a supply chain. Overall, our study reveals the following insights.

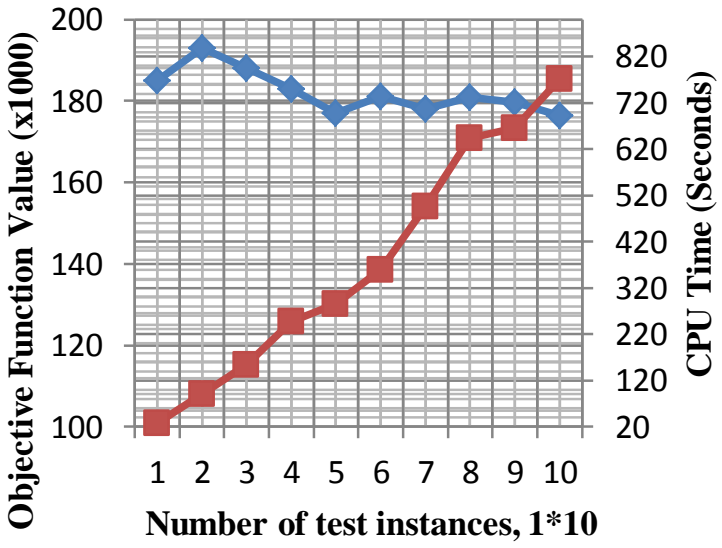

- Objective - CPU time

Figure 3. Objective Function Value and CPU Time for Different Numbers of Scenarios

Firstly, it is observed that the solutions of the proposed model are highly sensitive to disruptions. The supply chain models with disruptions claim approximately two to five times higher cost than the basic model. The cost due to disruptions increases at a faster rate for higher number of customers. Secondly, selections of location for distribution centers as well as shipment decisions are changed in many instances while we link disruptions handling cost to the basic model. This is one of most interesting findings worth mentioning in this work. To minimize the impacts and costs associated with disruptions, the model seeks different location (DCs) and different supplies portfolio. Thus, we have considerably different distribution strategy when we include disruptions. Thirdly, it is seen that the objective function value tend to become lower for higher number of scenarios. The expected total cost is likely to be stable and lower in the case of increased number of scenario sets. As a result, the objective function values become lesser for the increased number of scenarios.

There are some ways by which this research can be extended in future work. Firstly, one could think of enhancing the model by including inventory management perspective under an integrated multi-period locationrouting- inventory model. Secondly, we consider supply and storage facility disruptions in our proposed work. However, it might be worth interesting to further enhance the work 
when it comes to demand disruptions in addition to supply and facilities disruptions. Thirdly, it is noted that the proposed model is illustrated through hypothetical data. To be more realistic and promising in the field of disruptions management, it can be further investigated with dataset obtained from a real life case study. What's more, it is advisable to test the model by considering huge number of customers and potential locations for the distribution centers (DCs). By doing so, the model could overcome one of its limitations to use for practical purposes.

\section{REFERENCES}

Alfred, W., \& Friedrich, C. J. (1929). Alfred Weber`s theory of the location of industries. The University of Chikago Press: Chikago, IL.

Ali, S. M., \& Nakade, K. (2014). Scenario-based Supply Chain Disruptions Management Framework-A Quantitative Approach. Innovation and Supply Chain Management 8(3),pp. 81-91.

Atoei, F. B., Teimory, E., \& Amiri, A. B. (2013). Designing reliable supply chain network with disruption risk. International Journal of Industrial Engineering Computations 4, pp. 111-126.

Azad, N., Davoudpour, H., Saharidis, G. K. D., \& Shiripour, M. (2013). A new model to mitigating random disruption risks of facility and transportation in supply chain network design. The International Journal of Advanced Manufacturing Technology 70 (9-12), pp. 1757-1774.

Baghalian, A., Rezapour, S., \& Farahani, R. Z. (2013). Robust supply chain network design with service level against disruptions and demand uncertainties: A real-life case. European Journal of Operational Research 227, pp. $199-215$.

Bhatia, G., Lane, C., \& Wain, A. (2013). Building Resilience in Supply Chains. An initiative of the Risk Response Network in collaboration with Accenture; World Economic Forum: Geneva, Switzerland.

Bieniek, M. (2015). A note on the facility location problem with stochastic demands. Omega 55, pp. 53-60.

Chatzipanagioti, M., Iakovou, E., Vlachos, D., \& Hajidimitriou, Y. a. (2011). Trade Facilitation and Supply Chain Network Design. Operations and Supply Chain Management: An International Journal 4(2), pp. 99-107.

Chopra, S., \& Sodhi, M. S. (2004). Managing Risk To Avoid Supply-Chain Breakdown. MIT Sloan Management Review 46, pp. 53-62.

Clausen, J., Larsen, J., Larsen, A., \& Hansen, J. (2001). Disruptions Management. ORMS Today 28(5), pp. 4043.

Craighead, C. W., Blackhurst, J., Rungtusanatham, M. J., \& Handfield, R. B. (2007). The Severity of Supply Chain Disruptions: Design Characteristics and Mitigation Capabilities. Decision Sciences 38, pp. 131-156.

Cui, T., Ouyang, Y., \& Shen, Z.-J. M. (2010). Reliable Facility Location Design Under the Risk of Disruptions. Operations Research 58(4-Part-1), pp. 998-1011.

Dantrakul, S., Likasiri, C., \& Pongvuthithum, R. (2014). Applied p-median and p-center algorithms for facility location problems. Expert Systems with Applications 41(8), pp. 3596-3604.

Falasca, M., Zobel, C. W., \& Cook, D. (2008). A Decision Support Framework to Assess Supply Chain Resilience. In Proceedings of the 5th International ISCRAM Conference, USA, pp. 596-605.

Garcia-Herrerros, P., Wassick, J. M., \& Grossmann, I. E. (2013). Design of Supply Chains under the Risk of Facility Disruptions. Computer Aided Chemical Engineering 32(6), pp. 577-582.

Ghomi-Avili, M., Makui, A., Naghibi, S. B., \& Yadegari, E. (2013). Facility Location with the Disruption Risk in the Supply Chain Network Design. Journal of Basic and Applied Scientific Research 3(7), pp. 898-910.

Guha-sapir, D., Hoyois, P., \& Below, R. (2013). Annual Disaster Statistical Review 2013: The Numbers and Trends. Brussels, Belgium.

Heckmann, I., Comes, T., \& Nickel, S. (2015). A critical review on supply chain risk - Definition, measure and modeling. Omega 52, pp. 119-132.

Hendricks, K. B., \& Singhal, V. R. (2005). An Empirical Analysis of the Effect of Supply Chain Disruptions on Long-Run Stock Price Performance and Equity Risk of the Firm. Production and Operations Management 14, pp. 35-52.

Hishamuddin, H., Sarker, R. A., \& Essam, D. (2014). A recovery mechanism for a two echelon supply chain system under supply disruption. Economic Modelling, 38, pp. 555-563.

Ho, S. C. (2015). An iterated tabu search heuristic for the Single Source Capacitated Facility Location Problem. Applied Soft Computing 27, pp. 169-178.

Jabbarzadeh, A., Jalali Naini, S. G., Davoudpour, H., \& Azad, N. (2012). Designing a Supply Chain Network under the Risk of Disruptions. Mathematical Problems in Engineering, 2012, pp. 1-23.

Kelle, P., \& Miller, P. A. (2001). Stockout risk and order splitting. Decision Sciences 71, pp. 407-415.

Kim, Y., Chen, Y., \& Linderman, K. (2015). Supply network disruption and resilience. Journal of Operations Management 33, pp. 43-59.

Knemeyer, A. M., Zinn, W., \& Eroglu, C. (2009). Proactive planning for catastrophic events in supply chains. Journal of Operations Management 27, pp. 141-153.

Latour, A. (2001). Trial by fire: A blaze in Albuquerque sets off major crisis for cellphone giants-Nokia handles supply shock with aplomb as Ericsson of Sweden gets burned-was SISU the difference? Wall Street Journal, 1-6.

Li, Q., Zeng, B., \& Savachkin, A. (2013). Reliable facility location design under disruptions. Computers and Operations Research, 40(4), 901-909.

Ma, L., Li, J., \& Wang, H. (2010). Coordinate the Supply Chain with Risk-Averse Agents under CVaR Criteria. 2010 International Conference on Management and Service Science, pp. 1-4.

Meixell, M. J., \& Gargeya, V. B. (2005). Global supply chain design: A literature review and critique. Transportation Research Part E: Logistics and Transportation Review 41, pp. 531-550.

Melo, M. T., Nickel, S., \& Saldanha-da-Gama, F. (2009). Facility location and supply chain management - A 
review. European Journal of Operational Research 196, pp. 401-412.

Moritz, S., \& Pibernik, R. (2008). The optimal number of suppliers in the presence of volume discounts and diffrent compensation potentials-an analytical and numerical analysis. European Business School Research, (working paper).

Owen, S. H., \& Daskin, M. S. (1998). Strategic facility location: A review. European Journal of Operational Research 111, pp. 423-447.

Parlar, M., \& Perry, D. (1996). Inventory models of future supply uncertainty with single and multiple suppliers. Naval Research Logistics 43, pp. 191-210.

Paul, S. K., Sarker, R., \& Essam, D. (2014). Real time disruption management for a two-stage batch production-inventory system with reliability considerations. European Journal of Operational Research 237(1), pp. 113-128.

Qi, X., Bard, J. F., \& Yu, G. (2004). Supply chain coordination with demand disruptions. Omega 32, pp. 301-312.

Qi, X., Bard, J. F., \& Yu, G. (2006). Disruption management for machine scheduling: The case of SPT schedules. International Journal of Production Economics 103, pp. 166-184.

Raftani-amiri, Z., Fazlollahtabar, H., \& Mahdavi-Amiri, N. (2010). A Multi-period Supply Network of Food Products Based on Time-Windows with Sensitivity Analysis. Operations and Supply Chain Management: 3(2), pp. 105-116.

Rice Jr, J. B., \& Caniato, F. (2003). Building a secure and resilient supply network. Supply Chain Management Review 7, pp. 22-30.

Sahraeian, R., Bashiri, M., \& Ramezani, M. (2010). A Stochastic Multi-Product , Multi-Stage Supply Chain Design Considering Products Waiting Time in the Queue. In Proceedings of the 2010 International Conference on Industrial Engineering and Operations Management, Bangladesh, pp. 577-583.

Schmitt, A. J., \& Singh, M. (2012). A quantitative analysis of disruption risk in a multi-echelon supply chain.
International Journal of Production Economics 139, pp. $22-32$

Shariff, S., Moin, N., \& Omar, M. (2010). An Alternative Approach using Genetic Algorithm Based Heuristics for Capacitated Maximal Covering Location Allocation Problem. Operations and Supply Chain Management 3(1), pp. 36-48.

Shen, Z. M. a X. (2007). Integrated supply chain design models: a survey and future research directions. Optimization 3, pp. 1-27.

Snyder, L. V., \& Daskin, M. S. (2005). Reliability Models for Facility Location: The Expected Failure Cost Case. Transportation Science 39, pp. 400-416.

Tang, C. S. (2006). Perspectives in supply chain risk management. International Journal of Production Economics 103(2), pp. 451-488.

Tomlin, B. (2006). On the Value of Mitigation and Contingency Strategies for Managing Supply Chain Disruption Risks. Management Science 52(5),pp. 639657.

Vilko, J., \& Ritala, P. (2014). Service Supply Chain Risk Management. Operations and Supply Chain Management 7(3), pp. 139-140.

Wang, M., \& Abareshi, A. (2014). The Measurement Model of Supply Chain Uncertainty and Risk in the Australian Courier Industry. Operations and Supply Chain Management 7(3), pp. 89-96.

Xia, R., \& Matsukawa, H. (2014). Optimizing the supply chain configuration with supply disruptions. Lecture Notes in Management Science 6, pp. 176-184.

Xiaoqiang, Z. X. Z., \& Huijiang, F. H. F. (2009). Response to the supply chain disruptions with multiple sourcing. 2009 IEEE International Conference on Automation and Logistics, pp. 136-139.

Yang, J., Qi, X., \& Yu, G. (2005). Disruption management in production planning. Naval Research Logistics 52(5), pp. $420-442$.

Yu, H., Zeng, A., \& Zhao, L. (2009). Single or dual sourcing: decision-making in the presence of supply chain disruption risks. Omega 37, pp. 788-800.

Zhu, G., Bard, J. F., \& Yu, G. (2005). Disruption management for resource-constrained project scheduling. Journal of the Operational Research Society 56, pp. 365-381.

Syed Mithun Ali is a graduate student in the Department of Architecture, Civil Engineering and Industrial Management Engineering in Nagoya Institute of Technology, Nagoya, Japan. Previously he served as an Assistant Professor in the Department of Industrial and Production Engineering (IPE) in Bangladesh University of Engineering and Technology (BUET), Bangladesh. His research appears in International Journal of Production Research, Management Science Letters, International Journal of Operations and Quantitative Management, Innovations and Supply Chain Management etc. His research interest includes supply chain disruptions management and application of artificial intelligence in manufacturing /service planning and decision making.

Koichi Nakade is from Japan. This author is a member of the Operations Research Society of Japan. The author has achieved both his Bachelor of Science and Master of Science in Engineering from Kyoto University, Kyoto, Japan in 1986 and 1988 respectively. He received a PhD from Nagoya Institute of Technology, Nagoya, Japan. His research is focused in the area of Operations Research. Currently, he is a Professor in the Department of Architecture, Civil Engineering and Industrial Management Engineering at Nagoya Institute of Technology, Japan. His research appears in European Journal of Operational Research, Computers and Industrial Engineering, International Journal of Productions Economics, etc. His research interest covers the Analysis of Stochastic Models as Queues, Markov Processes, Game Theory, and Inventory Models and their Applications to Production Systems and Supply chain. 